\title{
The Choir Books of San Giorgio Maggiore in Venice: Results of in Depth Non-Invasive Analyses
}

\author{
Paola Ricciardi ${ }^{1, t, *} \mathbb{\infty}$, Anna Mazzinghi ${ }^{1,2,+, *} \mathbb{\infty}$, Stefano Legnaioli ${ }^{3}$, Chiara Ruberto ${ }^{2,4}$ and \\ Lisa Castelli ${ }^{2}$ \\ 1 The Fitzwilliam Museum, University of Cambridge, Cambridge CB2 1RB, UK \\ 2 INFN/CHNet, Florence Division, 50019 Sesto Fiorentino, Italy; ruberto@fi.infn.it (C.R.); \\ lisa.castelli@fi.infn.it (L.C.) \\ 3 ICCOM-CNR, 56124 Pisa, Italy; s.legnaioli@pi.iccom.cnr.it \\ 4 Department of Physics and Astronomy, University of Florence, 50019 Sesto Fiorentino, Italy \\ * Correspondence: pr364@cam.ac.uk (P.R.); mazzinghi@fi.infn.it (A.M.) \\ + These authors contributed equally to this work.
}

Received: 31 May 2019; Accepted: 12 June 2019; Published: 14 June 2019

check for updates

\begin{abstract}
This paper discusses a cross-disciplinary, international collaboration aimed at researching a series of 15th century choir books at the abbey of San Giorgio Maggiore on the homonymous island in Venice. Produced for the abbey itself, the books have never left the island during their 500-year history, thereby allowing a unique opportunity to analyse historic artefacts, which have undergone little modification over time. Prompted by ongoing cataloguing work on the manuscripts, a week-long analytical campaign using a combination of non-invasive analytical methods used in portable configuration allowed the comprehensive characterisation of ten volumes. The manuscripts' palette and painting techniques were analysed using near-infrared imaging, reflectance spectroscopy in the UV-vis-NIR range, Raman spectroscopy, X-ray fluorescence mapping and digital microscopy. The paper will discuss the challenges linked to the fragility and the large dimensions of the volumes as well as the most interesting results of the investigation. These include the detection of unusual painting materials such as bismuth ink, as well as the discovery of a less homogeneous palette than originally expected, which prompted a partial revision of the attribution of the decoration in one of the volumes to a single artist.
\end{abstract}

Keywords: 15th-century illuminated manuscripts; smalt; bismuth ink; non-invasive analyses; Raman spectroscopy; XRF mapping; UV-vis-NIR reflectance spectroscopy

\section{Introduction}

The abbey of San Giorgio Maggiore in Venice owns a precious set of 15th century manuscripts which have never left the island since their production for the abbey itself. This makes the volumes of particular interest, as their miniatures have undergone little or no intervention during their long history. Over time, however, the volumes have been disassembled and reassembled in various ways, which brings complexity to the current cataloguing work carried out by local scholars. Such work can be supported by the analytical investigation of the volumes' pigment palette and painting techniques, which might help identify the origin of displaced leaves and provide further evidence for the attribution of individual illuminations to certain artists. This paper discusses the non-invasive diagnostic campaign carried out on site in June 2018.

The scientific analysis of manuscripts is often challenging for a number of reasons. Firstly, there are practical constraints linked to the difficulty or impossibility to remove the manuscripts from their location, due to their fragility, value and environmental sensitivity. On-site work with portable 
equipment is usually recommended. In this particular case, however, transport of the instrumentation to a small island in the Venetian lagoon was not particularly straightforward. Positioning the instruments in front of bound volumes can also be physically complicated especially in the case of very large and heavy books. Most of the San Giorgio manuscripts measure approximately $70 \times 50 \times 8 \mathrm{~cm}$ and weigh several kilograms each, thus requiring handling by two people at a time. In order to establish the manuscripts' palette and painting techniques as comprehensively as possible, a wide range of complementary analytical methods were carefully chosen to be used in combination. The collaborative effort of researchers with complementary technical skills from three different institutions allowed to maximise the time spent with the manuscripts. Close communication with the scholars involved in the ongoing cataloguing effort was key to establishing the main research questions the analyses could help answer and to selecting a limited number of folios on which the investigation should focus.

\section{Methods and Materials}

\subsection{Analytical Protocol}

During the past few decades, numerous analytical methods have been used to analyse manuscripts, with a preference for non-invasive approaches, due to the value and fragility of these objects. A comprehensive review of the relevant literature is beyond the scope of this article; suffice it to say that the methods used to study manuscript vary from quick and easy imaging methods to complex and time-consuming highly-specific chemical analyses [1,2]. Non-invasiveness of the analysis and portability of the scientific equipment are key characteristics, which often determine the choice of methods to be used. In this study, the identification of pigments and painting techniques was achieved by means of several analytical methods, used in combination for a comprehensive characterisation of the materials. A multi-step analytical protocol was used, starting with near-infrared (NIR) imaging followed by spectroscopic analyses: fibre-optic reflectance spectroscopy (FORS) in the ultraviolet, visible and near-infrared (UV-vis-NIR) range; X-ray fluorescence (XRF) mapping; and Raman spectroscopy. Selected areas were then imaged with a digital optical microscope in order to visualise minute details and to clarify the results of the spectroscopic analyses, e.g. by identifying the presence of pigment mixtures.

NIR images were taken with a 5-megapixel camera (Spectrocam by Pixelteq) equipped with 8 filters covering the spectral range from $400 \mathrm{~nm}$ to $1000 \mathrm{~nm}$. The system allows to take multiple images of the same object at different wavelengths. For the purpose of NIR imaging, we used either an $800 \mathrm{~nm}$ long-pass filter or a $925 \mathrm{~nm}$ band-pass filter with $50 \mathrm{~nm}$ FWHM. Exposure times were adjusted for each filter individually and ranged from $100 \mathrm{~ms}$ to $2 \mathrm{~s}$. Illumination was provided by a a lamp fitted with a low voltage $35 \mathrm{~mW}$ SoLux bulb (colour temperature $4700 \mathrm{~K}$, beam-spread $36^{\circ}$ ).

FORS spectra were acquired in the 350-2500 nm range using a FieldSpec4 fibre optic spectroradiometer (ASD Inc., Boulder, Colorado, USA). The instrument's resolution is $3 \mathrm{~nm}$ at $700 \mathrm{~nm}$, and $10 \mathrm{~nm}$ at 1400 and $2100 \mathrm{~nm}$, and the wavelength accuracy is $0.5 \mathrm{~nm}$. Spectra were collected and processed using ASD's RS3 and ViewSpec Pro software as well as Origin Pro 8.6 (OriginLab, Northampton, MA, USA). Spectra were an average of 64 accumulations, for a total measurement time of just over $8 \mathrm{~s}$ per spectrum. The bifurcated fibre probe, which delivers illumination to the area under analysis and collects the reflected signal, was held normal to the manuscript page. The identification of materials was achieved by comparison with online and in-house spectral databases of reference pigments and mixtures painted on various supports and bound in different media [3].

XRF spectra and maps were acquired with a custom-made instrument designed and developed by the CHNet (Cultural Heritage Network) of the Istituto Nazionale di Fisica Nucleare (INFN), during a project headed by the LABEC laboratory in Florence. The instrument is described in detail elsewhere [4]. Briefly, the instrument consists of a measuring head fitted with a Mo-anode X-ray tube (Moxtek@, $40 \mathrm{kV}$ maximum voltage, $0.1 \mathrm{~mA}$ maximum anode current) and a SDD detector (Amptek@), which is mounted on a three-axis precision positioning stage (Physik Instrumente $\subseteq$, $300 \mathrm{~mm}$ travel range 
in the $\mathrm{x}$ direction and 150 in the $\mathrm{y}$ direction for this version). A dynamic positioning system controls and adjusts the working distance during scanning. An $800 \mu \mathrm{m}$ collimator was used during the measurements discussed here. The standard operating conditions for all measurements were: $25 \mathrm{kV}$ anode voltage, $50 \mu \mathrm{A}$ filament current, $1 \mathrm{~mm} / \mathrm{s}$ scanning velocity and $500 \mu \mathrm{m}$ pixel size. The instrument was positioned over a custom-made 'bridge' platform, wide enough to rest on either side of the open book. Analyses were carried out on the folios held up vertically in front of the instrument by means of a Perspex support and kept stable with the help of conservation-grade polystrap (Figure 1). Areas too close to the volumes' binding could not be reached.

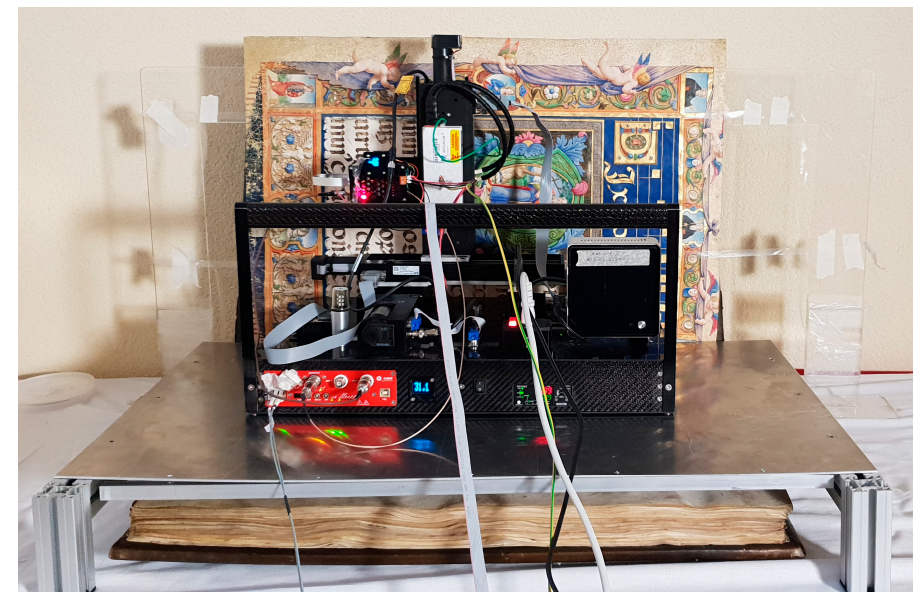

Figure 1. Setup for the XRF scanning system.

Raman analyses were carried out with a portable i-Raman Plus spectrometer (B\&W TEK Inc., Newark, USA) provided with a $785 \mathrm{~nm}$ excitation laser line and a high quantum efficiency CCD array detector. The spectral range of the spectrometer is $65-3350 \mathrm{~cm}^{-1}$ with a resolution of $3.9 \mathrm{~cm}^{-1}$. The spectrometer and laser were connected to a probe head with optical fibres. The Raman microprobe was attached to a video microscope with an integrated camera and an LED illuminator to allow precise identification of the spot analysed. The video microscope with the Raman micro-probe was mounted on a tripod with a $\mathrm{x}-\mathrm{y}$ micro-stage. A $40 \mathrm{x}$ long-distance objective lens was used, providing a laser spot size about $50 \mu \mathrm{m}$ in diameter. The laser power used during the measurements was kept below $0.2 \mathrm{~mW}$ at all times to prevent pigment photodecomposition. Typical acquisition times were of the order of $10-40 \mathrm{~s}$. The identification of materials was achieved by comparison with published spectral databases of reference pigments [5,6].

Detail images of the manuscripts were collected using a DinoLite microscope with magnification ranging from $20 x$ to $200 x$.

\subsection{The Manuscripts}

The abbey of San Giorgio Maggiore holds a set of fifteen volumes, most of which are illuminated, largely produced during the 15th and the 16th century. They are all liturgical choir books: Antiphonaries, Psalters, Kyrials and Graduals, containing for example songs for the Liturgy of the Hours or for the celebration of the daily Mass. Academic research on the volumes has identified the hands of well-known artists in the illuminations, including Belbello da Pavia and Cristoforo Cortese. Other-equally proficient-illuminators remain unnamed, and are known only for their work on these volumes; these include the so-called Master of Antiphonary M and the Master of Antiphonary Q. The latter artist's work is now spread across at least six volumes, due to the disbinding of the volumes which has taken place in the past. Scholars believe that illuminations attributed to the Master, and currently inserted in volumes other than Antiphonary $\mathrm{Q}$, would have belonged to one or possibly two additional volumes, now lost [7]. 
Painting materials and techniques were analysed in selected folios of nine volumes within the set, listed in Table 1 together with a Missal containing illuminations also attributed to Cristoforo Cortese. The latter volume has been recently acquired by the abbey and was included in the analytical campaign in order to provide a useful comparison with other illuminations by Cortese. The selection of manuscripts and individual folios for analysis was based on a discussion with the scholars involved in the ongoing cataloguing effort and was aimed at establishing the main research questions the analyses could help answer, such as the potential division of labour between Cristoforo Cortese and his workshop assistant(s) in Psalter N.

\section{Results}

\subsection{Overview}

Many of the materials identified during the analyses were used by most of the artists; this is in no way surprising, considering that 15th-century illuminators had a relatively small range of pigments at their disposal. Table 1 summarises the results of the analyses, the most interesting of which will be discussed in detail in the following sections.

The shared palette included malachite, used as a green pigment in all the analysed manuscripts. Vermilion was also used extensively, as was an organic red colourant, likely insect-based, which was mixed with lead white to obtain a range of pink hues. No evidence for gypsum mixed with the red dye was found. Lead-tin yellow was the only yellow pigment found in the manuscripts. Whenever Raman analyses were performed, this was found to be lead-tin yellow type I. Most brown areas were painted with complex and diverse mixtures of earth pigments, vermilion, indigo and red lead. Flesh tones were usually found to contain lead white and vermilion; the presence of additional pigments such as earths and ochres could not be proven in most cases but cannot be conclusively excluded. Mosaic gold (tin disulphide) was only identified in four of the manuscripts, whereas every single volume contains gold leaf. The composition of the underlying ground layer ('bole') could only be analysed occasionally, as the well-preserved gold leaf did not usually allow direct access to the bole. When data were successfully acquired, the bole was found to be traditionally composed of gypsum and a red earth or clay. In some cases, vermilion was also identified in the bole. A detailed analysis of the inks used to write the text was outside the scope of this research; however, inks were briefly tested in each manuscript and found to be traditional iron-gall inks. 
Table 1. List of volumes and folios analysed, with the main pigments and mixtures identified. Attributions to individual artists* are based on a forthcoming scholarly catalogue [7]. LTY: lead tin yellow. Az: azurite. n/a indicates the suspected presence of a pigment based on visual examination but not confirmed analytically.

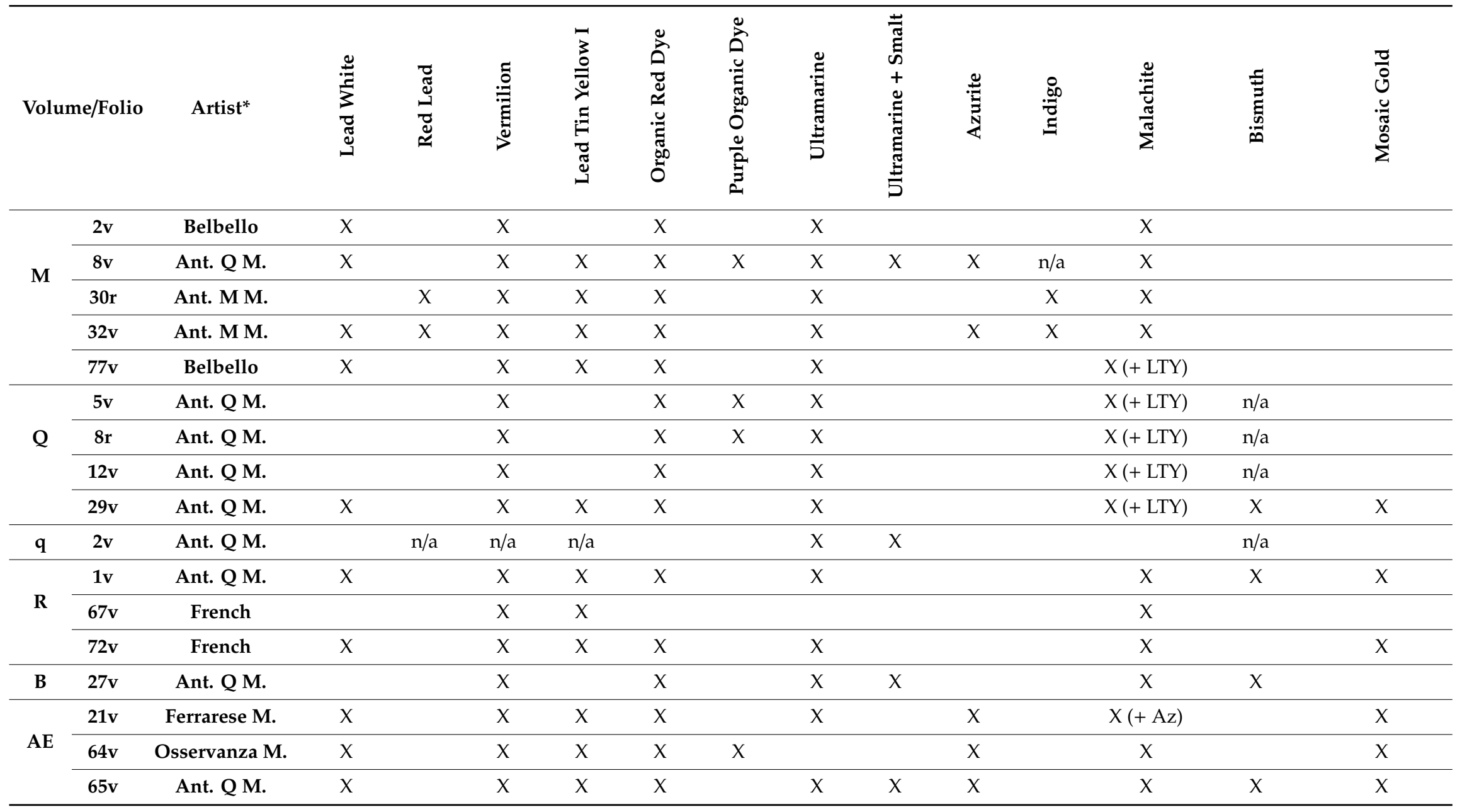


Table 1. Cont.

\begin{tabular}{|c|c|c|c|c|c|c|c|c|c|c|c|c|c|c|c|}
\hline \multicolumn{2}{|c|}{ Volume/Folio } & Artist $^{*}$ & 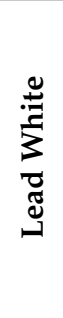 & 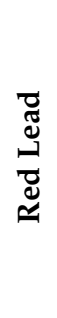 & 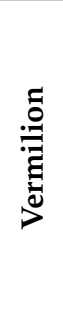 & 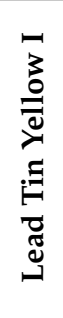 & 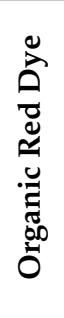 & 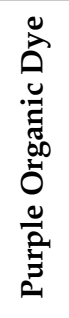 & 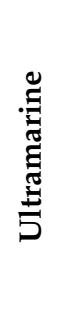 & 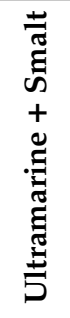 & 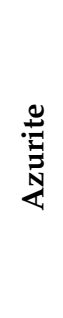 & $\underset{\Xi}{\stackrel{0}{\sigma}}$ & 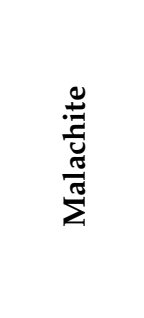 & 节 & 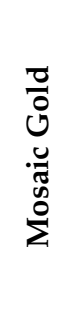 \\
\hline $\mathbf{K}$ & $1 \mathrm{r}$ & Ferrarese M. & $x$ & & $x$ & & & & $x$ & & & & $x$ & & \\
\hline \multirow{6}{*}{$\mathbf{N}$} & $17 v$ & Cortese & $x$ & $x$ & & $x$ & $x$ & & & & $x$ & & $x$ & & $\mathrm{n} / \mathrm{a}$ \\
\hline & $20 v$ & Cortese & & $x$ & & & $x$ & & & & $x$ & & $x$ & & $x$ \\
\hline & $36 r$ & Cortese & $x$ & $x$ & $x$ & & $x$ & & & & $x$ & & $x$ & & $\mathrm{n} / \mathrm{a}$ \\
\hline & $99 \mathrm{r}$ & Cortese & & & $x$ & & $x$ & & & & $X$ & & $X(+A z)$ & & \\
\hline & $107 v$ & Cortese & $x$ & & $x$ & & $x$ & & & & $x$ & & $x$ & & $\mathrm{n} / \mathrm{a}$ \\
\hline & $150 \mathrm{r}$ & Cortese & & & $x$ & & $x$ & & & & $x$ & & $X(+A z)$ & & $x$ \\
\hline $\begin{array}{l}\text { Missa } \\
\text { CXII }\end{array}$ & 100r & Cortese & & & $x$ & & $x$ & & & & $x$ & & $x$ & & \\
\hline
\end{tabular}

*Belbello: Belbello da Pavia; Ant. Q M.: Master of the Antiphonary Q; Ant. M M.: Master of the Antiphonary M; French: (unnamed) French Master; Ferrarese M.: Ferrarese Master; Osservanza M.: Master of the Osservanza; Cortese: Cristoforo Cortese. 
There is great variety amongst the manuscripts in the use of blue pigments, which deserve further discussion and serve as a good example of the importance of employing a multi-technique approach. Three different blue pigments were identified, for example, in folio 32v of Antiphonary M (Figure 2a). As seen in the NIR image (Figure 2b), the green initial and leaves appear dark, suggesting the use of a copper-based compound. Most of the blue background inside the initial appears light, excluding the presence of azurite. Some areas close to the saint's figure and the scroll however appear dark, meaning that azurite might have been used selectively. These observations are supported by the XRF maps (Figure 3a); the $\mathrm{K}-\mathrm{K} \alpha$ map suggests the use of ultramarine in most blue areas (no cobalt was identified, therefore the presence of potassium could not be due to smalt), whereas the $\mathrm{Cu}-\mathrm{K} \alpha$ map shows how azurite was used for outlining and shadowing. The light blue leaves in the upper-right and bottom-left corner of the initial are visible in both maps, suggesting a mixture of ultramarine and azurite. This is reflected in their appearance in mid-grey tones in the NIR image. FORS analysis (Figure 3b) confirms the identification of the materials mentioned above and provides additional information, for example by proving the presence of indigo (max absorption at $660 \mathrm{~nm}$ ), mixed with lead white (absorption bands at 1447 and $2321 \mathrm{~nm}$ ), in the shadowed areas of the white scroll held by the saint. Raman analysis (Figure 3c) confirmed that indigo was also used in the muddy-green landscape (peaks at $545(\mathrm{w})$ and $\left.1572(\mathrm{w}) \mathrm{cm}^{-1}\right)$, in a mixture with lead-tin yellow. The latter pigment (peaks at $128(\mathrm{vs}), 195(\mathrm{~m}), 270(\mathrm{w})$ and $454(\mathrm{w}) \mathrm{cm}^{-1}$ ) also provided highlights in the saint's rainbow-coloured robe.
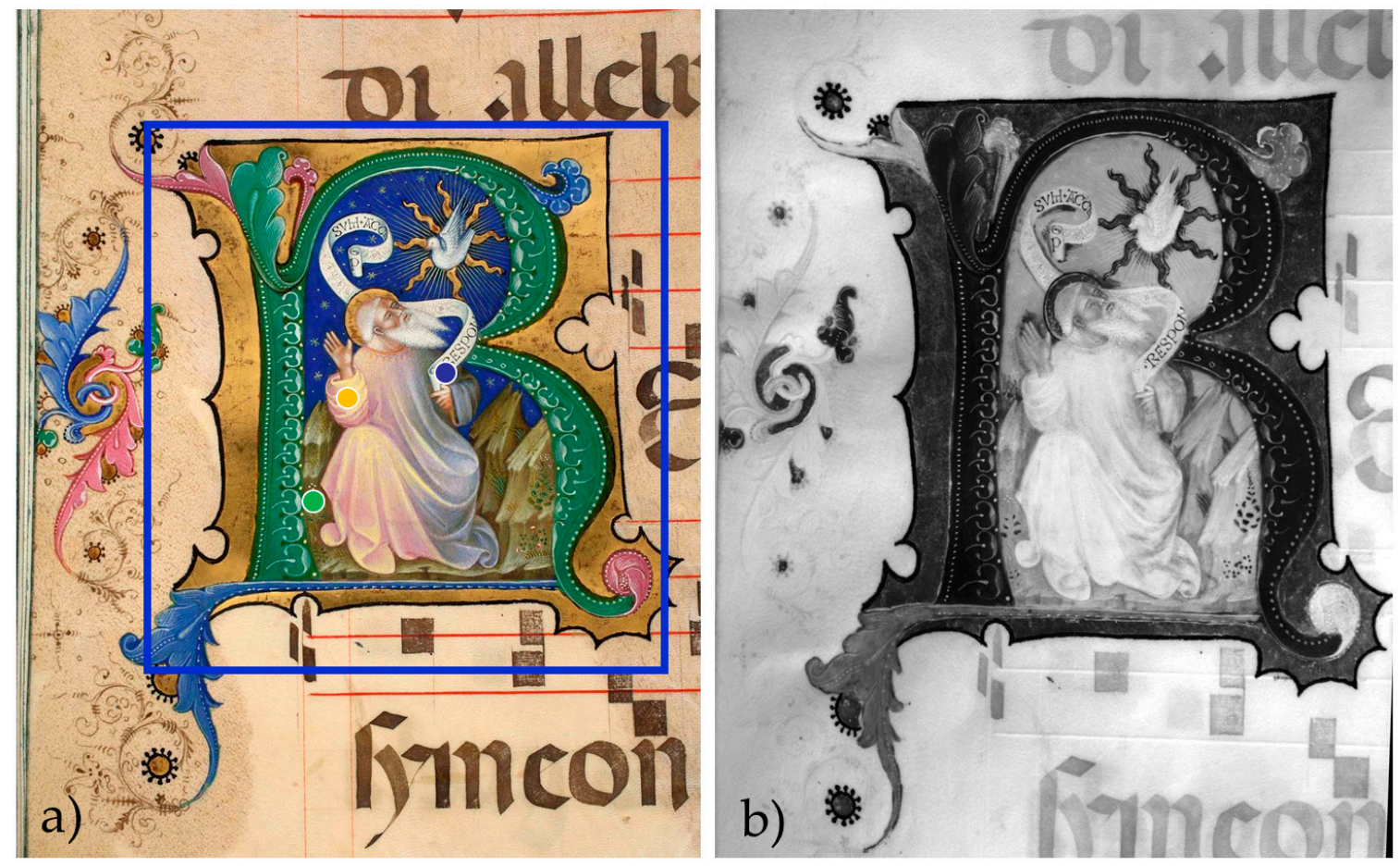

Figure 2. Antiphonary $M$, folio 32v (a) Visible detail, with coloured dots indicating where spectra shown in Figure 3 were acquired; (b) NIR image ( $925 \mathrm{~nm}$ filter). 
a)
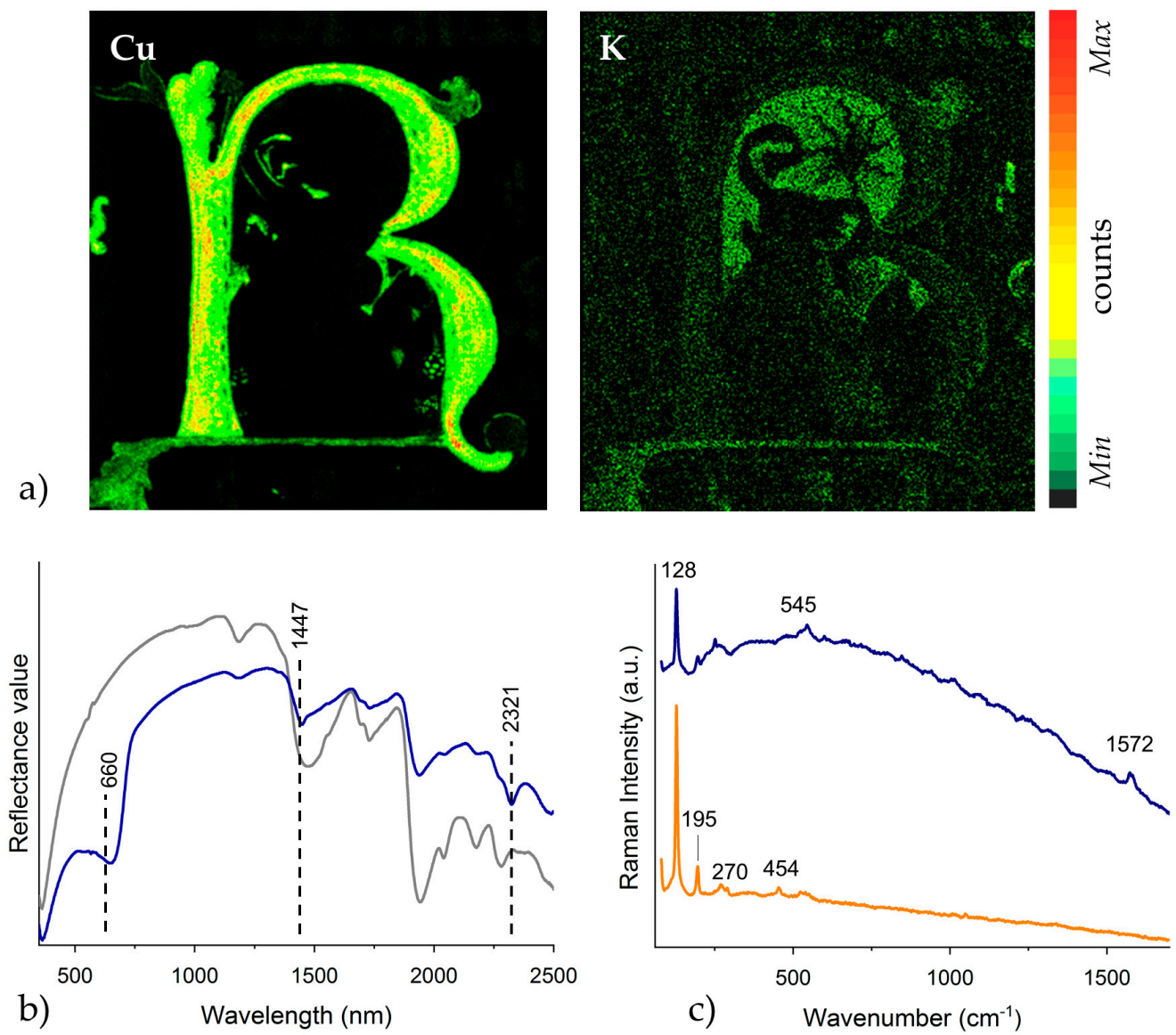

Figure 3. Antiphonary $\mathrm{M}$, folio $32 \mathrm{v}$ (a) XRF maps of $\mathrm{Cu}-\mathrm{K} \alpha$ and $\mathrm{K}-\mathrm{K} \alpha$ in the area outlined in blue in Figure 2a; (b) FORS spectra of bare parchment (grey trace) and white scroll (blue trace); (c) Raman spectra of a yellow highlight on the saint's robe (orange trace) and of the muddy green of the rocky landscape (green trace). Spectra are offset for clarity.

\subsection{Illuminations Attributed to Cristoforo Cortese}

All the miniatures in the two San Giorgio manuscripts attributed to Cristoforo Cortese (Psalter N and Missal CXII) have a shared palette which includes azurite, lead white, an organic red colourant (likely insect-derived) mixed with lead white, mosaic gold and carbon black (used for outlines). Malachite is the main green pigment, used in all the miniatures. On folios 99r and 150r of Psalter N, malachite is mixed with azurite, yielding a slightly different shade of green.

A significant visual difference within the numerous miniatures in Psalter $\mathrm{N}$ regards the orange and red areas. Some of the miniatures are characterised by bright orange layers, highlighted with thick yellow and white brushstrokes (Figure $4 a, c)$. Others, instead, have a slightly more sombre palette, with darker red hues dominating, and thin white highlights only (Figure $4 b, d$ ). We could only identify two cases in this volume, where orange was painted over red (in folios $7 \mathrm{v}$ and $36 \mathrm{r}$, see Figure $4 \mathrm{e}$ ). FORS and Raman analyses (Figure 5a,b) confirmed the use of vermilion and red lead for the red and orange areas, respectively. Vermilion was identified by its transition edge around $605 \mathrm{~nm}$ in the FORS spectra and by Raman peaks at $254(\mathrm{~s})$ and $345(\mathrm{~m}) \mathrm{cm}^{-1}$. Red lead showed its typical $570 \mathrm{~nm}$ transition edge and Raman peaks at $121(\mathrm{vs}), 142(\mathrm{~s}), 223(\mathrm{~m}), 310(\mathrm{~m})$ and $548(\mathrm{~s}) \mathrm{cm}^{-1}$. The presence of additional peaks at 286 (s) and $388(\mathrm{~s}) \mathrm{cm}^{-1}$, together with the unexpectedly high intensity of the peak at $142 \mathrm{~cm}^{-1}$ suggest the additional presence of massicot. The latter is often found alongside red lead in historic manuscripts, either as a residue of the roasting process of the lead-based red pigment, or as an impurity of the natural lead tetroxide mineral minium. 

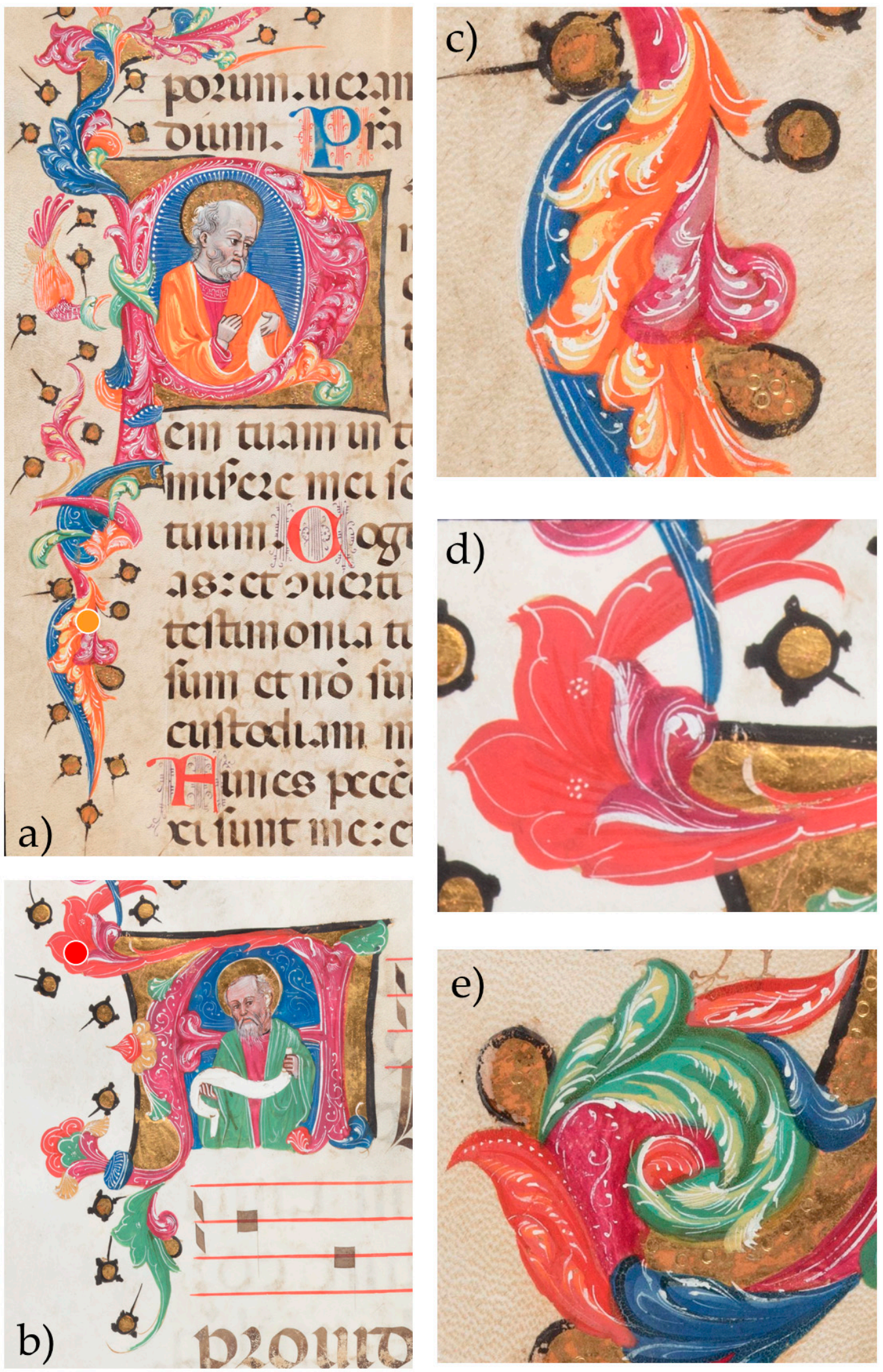

Figure 4. Analysis of red and orange areas in Psalter N: (a) detail from folios $17 \mathrm{v}$ and (b) $107 \mathrm{v}$, with coloured dots indicating where spectra shown in Figure 5 were acquired; (c) magnified detail of orange leaf on folio $17 \mathrm{v}$; (d) magnified detail of red leaf on folio 107v; (e) magnified detail of leaf on folio $7 \mathrm{v}$, painted with orange over red. 

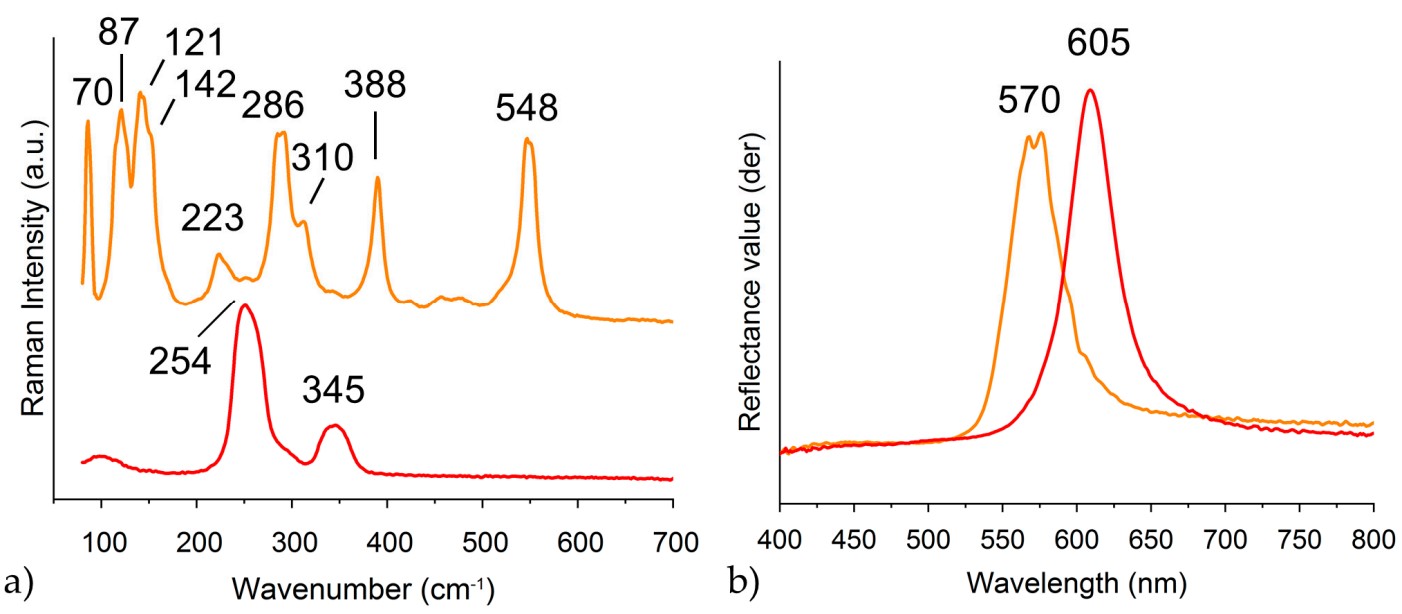

Figure 5. Analysis of red and orange areas in Psalter N: (a) Raman spectra of orange and red areas (spectra are offset for clarity); (b) first derivative of the FORS spectra of orange and red areas.

Missal CXII, whose illuminations are also attributed to Cristoforo Cortese despite the obvious overall stylistic differences (see Figure 6), does not contain any orange areas; vermilion alone was identified in all red areas analysed in the manuscript.
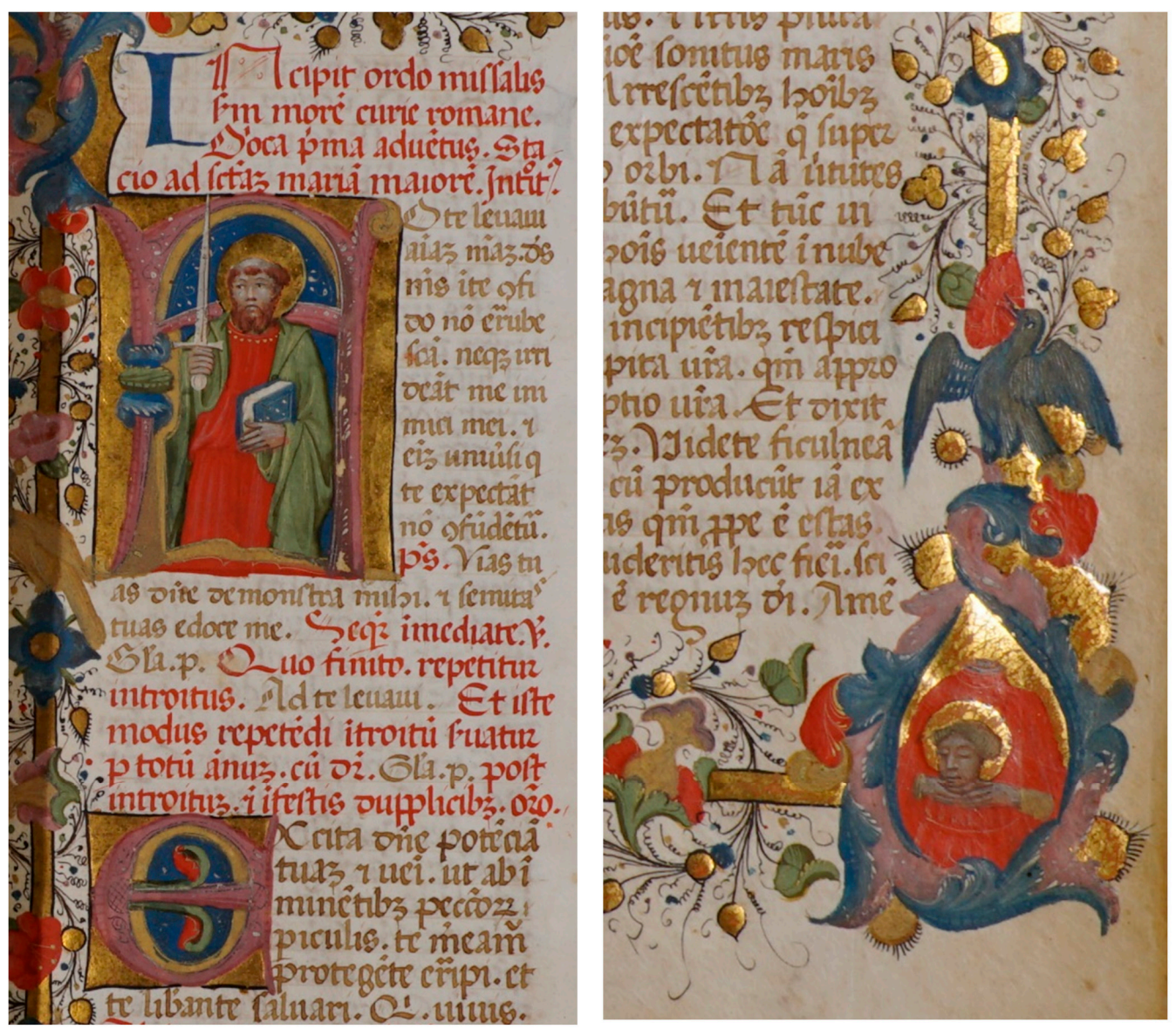

Figure 6. Missal CXII, details from folio 1r. 


\subsection{The Identification of Smalt in Miniatures Attributed to the Master of Antiphonary $Q$}

Nine of the miniatures analysed are attributed to the Master of Antiphonary Q; four of them are included in his eponymous manuscript, whereas the remaining five are spread across five additional volumes (see Table 1). Overall, a shared palette was indeed identified within the miniatures present on these folios. It includes ultramarine, vermilion, lead white, malachite, as well as lead-tin yellow type I. The latter is often also mixed with malachite in green areas and used to outline and highlight red areas. None of the miniatures contain red lead. Gold leaf was used extensively, whereas shell silver appears to have only been used to depict a light grey fish in folio $7 \mathrm{v}$ of Antiphonary $\mathrm{Q}$. The results presented here focus on the miniatures rather than on the decorative borders, also present on the same pages, which were likely executed by workshop assistants and therefore have no bearings on the attribution to the Master of Antiphonary Q.

NIR imaging reveals some differences among the nine miniatures, two of which are shown in Figures 7 and 8 as an example. In Antiphonary Q, folio 5v, the infrared image reveals little or no underdrawing. In Antiphonary M, folio 8v, however, NIR imaging reveals the likely presence of underdrawing, traced with a dry medium, as well as the presence of cross-hatching-used to indicate modelling - in the shadows. This is especially visible in the Virgin's dark pink robe. These observations may suggest that the miniatures were designed, if not painted, by two different artists.

Additional differences were observed in the use of blue pigments within the miniatures, especially in light blue areas. Pure ultramarine was identified in these areas, in the four miniatures within Antiphonary $Q$, as well as in the image on folio $1 \mathrm{v}$ within Antiphonary R. In the other four images, however (Antiphonary M, folio 8v; Antiphonary q, folio 2v; Gradual B, folio 27v; and Kyriale AE, folio $65 \mathrm{v}$ ), light blue hues contain a mixture of smalt and ultramarine. The combined presence of both blue pigments is confirmed by two of the three spectroscopic methods employed. In the Virgin's blue mantle depicted on folio 8v of Antiphonary M (Figure 7a), for example, FORS spectra of all blue areas (Figure 9a) display a narrow peak with maximum at $460 \mathrm{~nm}$, in addition to ultramarine's typical deep absorption centred at $600 \mathrm{~nm}$, followed by a sharp increase in reflectance. Uncharacteristically for ultramarine, however, reflectance drops again around $1200 \mathrm{~nm}$. This suggests the possible presence of a cobalt-containing pigment, which is confirmed by the elemental map for cobalt, obtained by fitting the Co K $\alpha$ XRF peak at $6.9 \mathrm{keV}$ (Figure 9b). Smalt's typical absorptions at 545, 600 and $640 \mathrm{~nm}$ can only be detected in the reflectance spectra of the lighter blue areas. This information, coupled with the slight differences between the elemental maps for cobalt, potassium, iron and calcium (see Supplementary Materials), reveal that the dark blue brushstrokes used to model the mantle contain ultramarine alone. Incidentally, the Virgin's mantle is also the only blue area within the Master of Antiphonary Q miniatures, which also contains small amounts of azurite, as revealed by weak absorption bands at 1495, 2285 and $2354 \mathrm{~nm}$ in the reflectance spectra (Figure 9a) and by widespread low signal for copper in the elemental maps (see Supplementary Materials).

Raman analysis of the blue mantle confirms the presence of ultramarine alone, characterised by a sharp peak at $548(\mathrm{~s}) \mathrm{cm}^{-1}$ (Figure 9c). The challenges of detecting smalt in ultramarine mixtures non-invasively are well known: smalt is difficult to detect by Raman spectroscopy, especially with a portable system equipped with a NIR source $[8,9]$ and it is only detected by FORS if present in relatively high amount [10]. The most reliable way to confirm its presence, even in very small percentages, is to use XRF spectroscopy, which can easily detect small amounts of cobalt. On the other hand, ultramarine is efficiently detected by Raman, but not easily picked out by FORS in a mixture with smalt, due to similar and not particularly specific spectral features. Similarly, ultramarine can go undetected through XRF analysis when smalt is also present, since the detectable elements (aluminium, silicon and potassium) are present in both pigments. To conclusively identify both components in a mixture of smalt and ultramarine, it is imperative to use a multi-analytical approach [10]. 


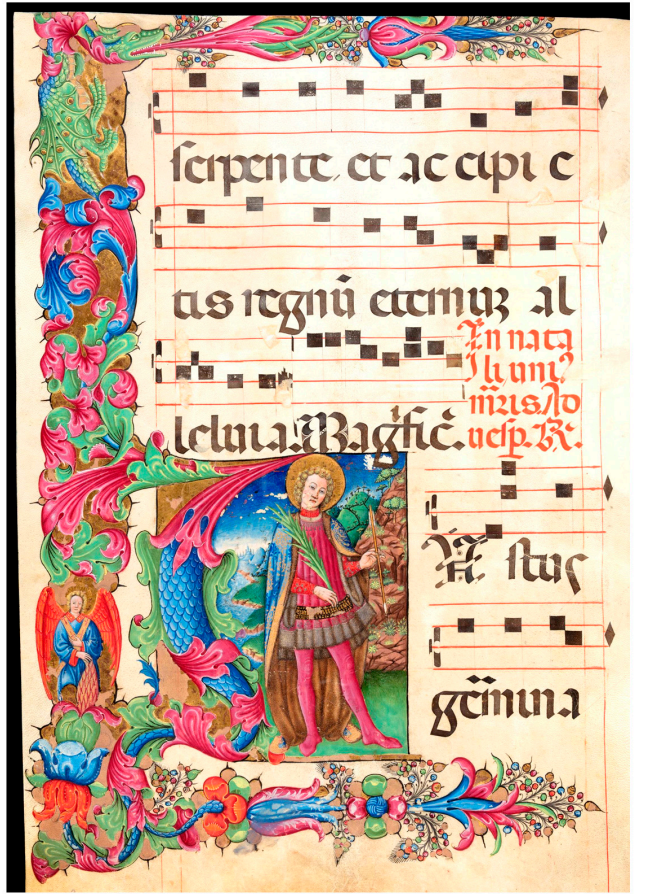

a)

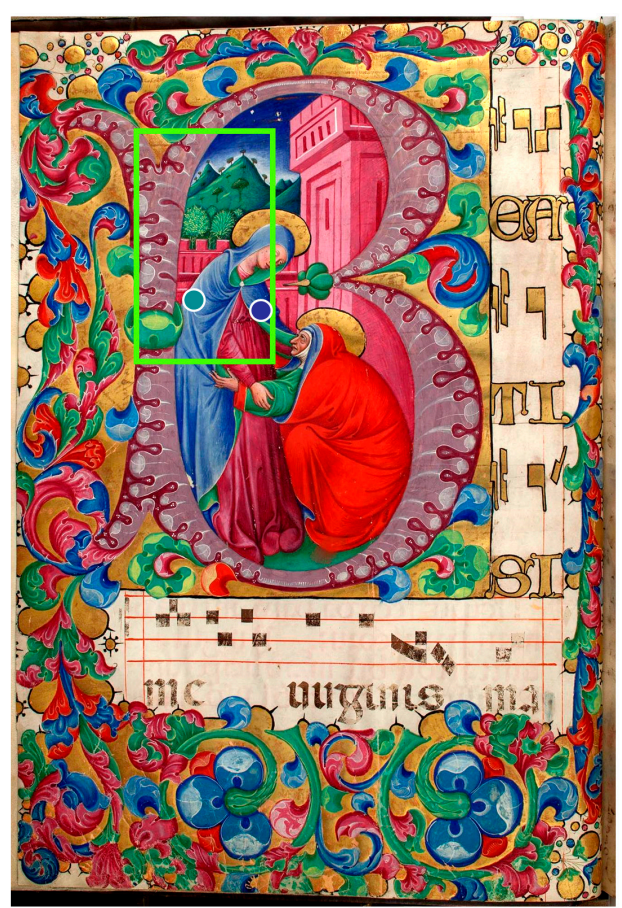

b)

Figure 7. Identification of smalt in the work of the Master of the Antiphonary Q: (a) Antiphonary Q, folio $12 \mathrm{v}$ and (b) Antiphonary M, folio 8v, with coloured dots indicating where spectra shown in Figure 9. were acquired.
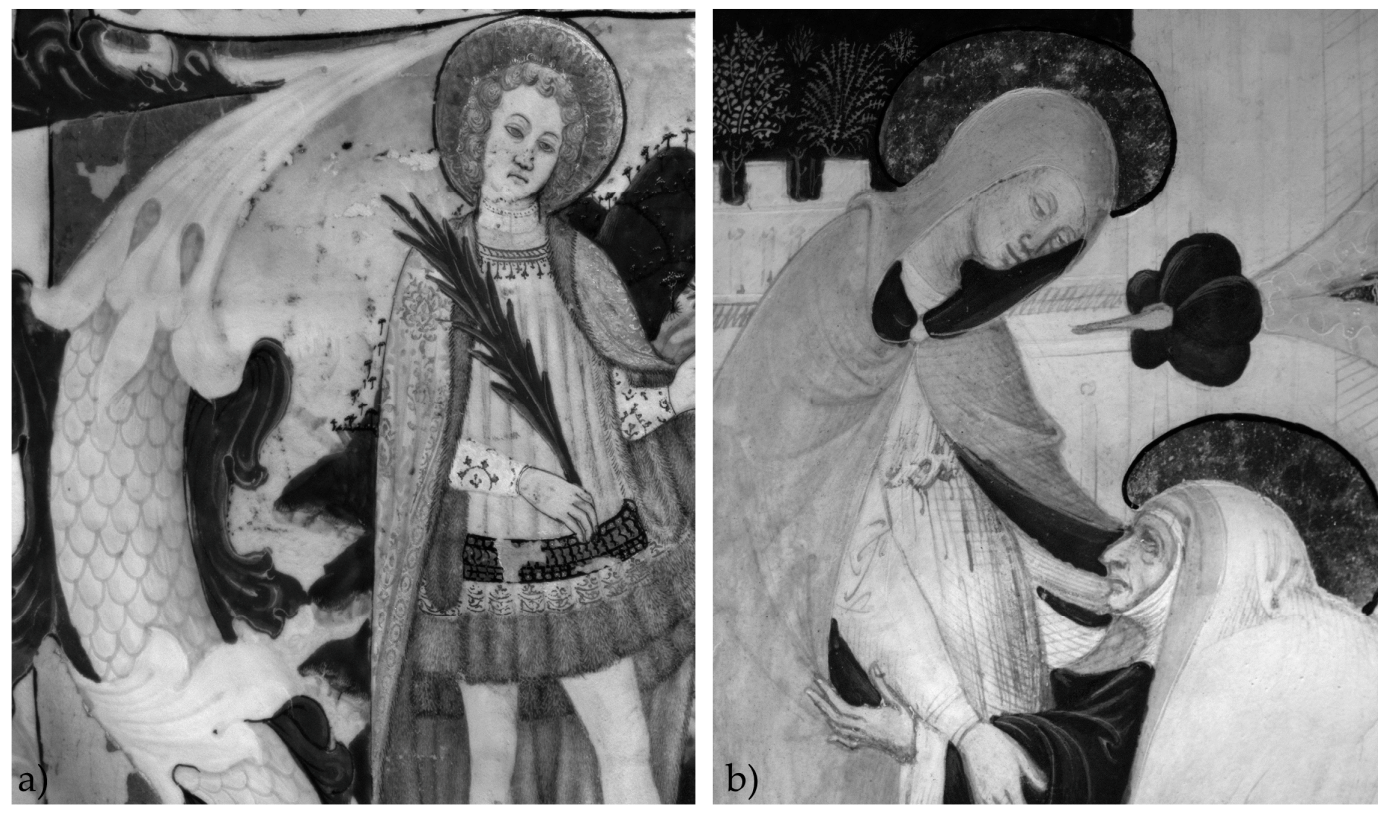

Figure 8. NIR details (800 nm long pass filter) of (a) Antiphonary Q, folio $12 \mathrm{v}$ and (b) Antiphonary $\mathrm{M}$, folio $8 \mathrm{v}$. 

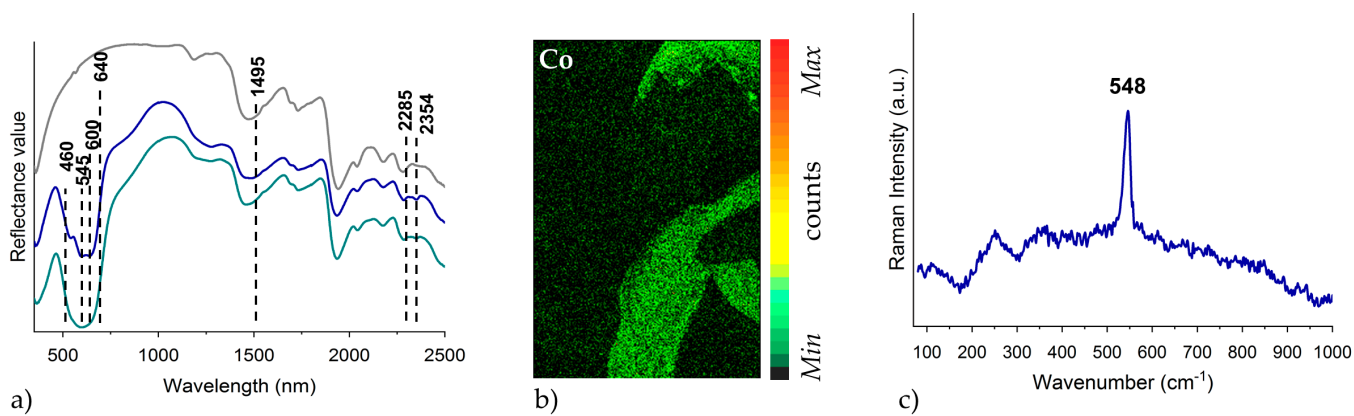

Figure 9. Analysis of blue areas on folio 8v of Antiphonary M (see Figure 7b): (a) FORS spectra of parchment (grey trace), light blue (blue trace) and dark blue (green trace) Virgin's mantle (spectra are offset for clarity); (b) XRF map of Co-K $\alpha$ in the area outlined in green in Figure $7 b$; (c) Raman spectrum of the Virgin's blue mantle.

\subsection{The Identification of Metallic Bismuth in Decorative Borders}

Decorative borders with thin black lines having a metallic appearance are present in seven out of the eight folios analysed with miniatures attributed to the Master of Antiphonary Q (see Figure 10a). The only exception is the large scene with the Visitation of the Virgin in Antiphonary M (Figure 7b).
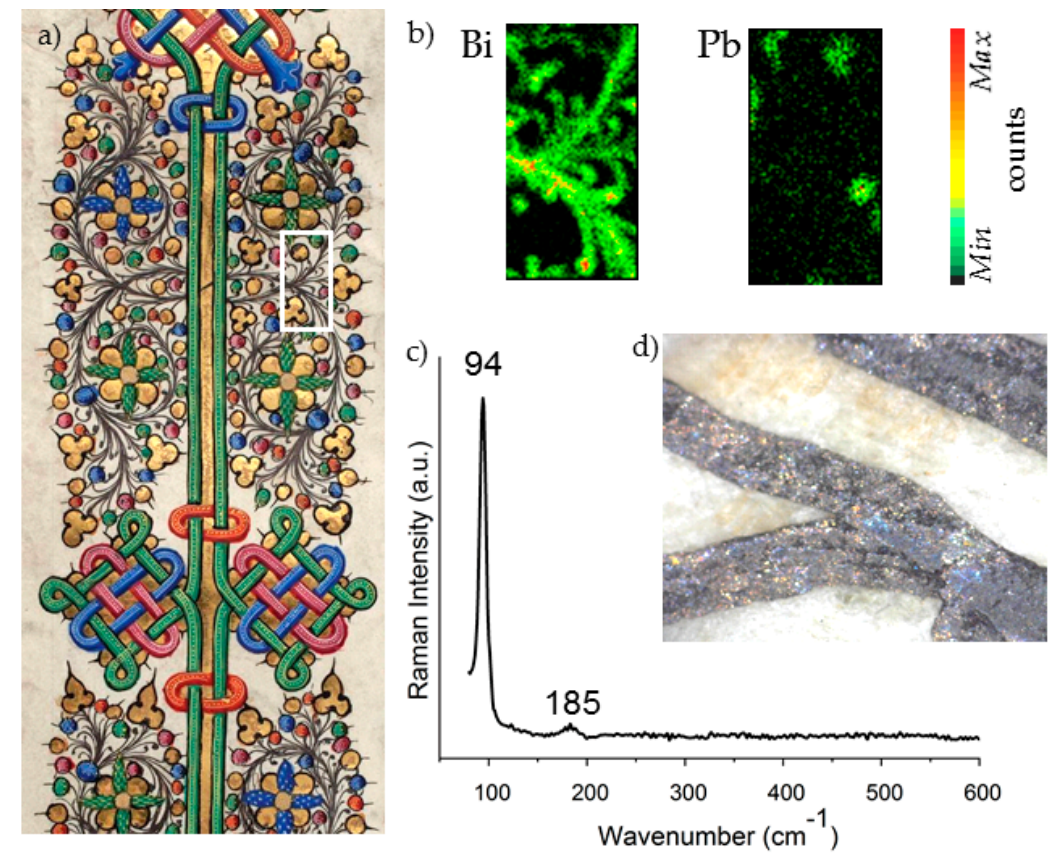

Figure 10. Identification of metallic bismuth in decorative borders: (a) Antiphonary $Q$, detail from folio 29v; (b) XRF maps of Bi-L $\alpha$ and $\mathrm{Pb}-\mathrm{L} \alpha$ in the area outlined in white in Figure 10a; (c) Raman spectrum of the black line within area outlined in white; (d) microscope image of the black line (original magnification 200X).

XRF mapping detected the characteristic X-ray lines of bismuth (Bi: $\mathrm{L} \alpha$ at $10.84 \mathrm{keV}, \mathrm{L} \beta$ at $13.02 \mathrm{keV})$. These could be clearly distinguished from the lead lines ( $\mathrm{Pb}: \mathrm{L} \alpha$ at $10.55 \mathrm{keV}, \mathrm{L} \beta$ at $12.61 \mathrm{keV}$ ), which have a completely different spatial distribution (Figure 10b). Raman spectroscopy (Figure 10c) identified the material as a metallic bismuth, with its characteristic peaks at 94 (vs) and $185(\mathrm{~m}) \mathrm{cm}^{-1}$ [11,12]. Under magnification (Figure 10d), these lines appear silvery grey with a reddish or pinkish iridescence, similarly to what has been observed by other scholars [11,12]. 


\section{Discussion}

\subsection{Cristoforo Cortese's Palette}

Cristoforo Cortese was one of the leading Venetian artists in the first half of the 15th century. His peculiar style, particularly the facial types and the feathery acanthus leaves decorating the initials, makes his work instantly recognisable [13].

Three manuscript fragments from the Fitzwilliam Museum's collection and one fragment from the Cini Foundation in Venice, all attributed to Cortese [14,15], have been analysed with an analytical protocol very similar to the one used during this work, and further detailed elsewhere [16]. It is thus interesting to compare the palette identified on these four illuminations, which likely to belong to phases of the artist's career-and further comparisons are possible with the Cortese illuminations found within the San Giorgio volumes. The pigments identified on the four fragments are summarised in Table 2, where the fragments are listed in their presumed chronological order.

Table 2. Pigments identified on four manuscript fragments with illuminations attributed to Cristoforo Cortese.

\begin{tabular}{|c|c|c|c|c|c|c|c|c|c|c|c|c|c|}
\hline & 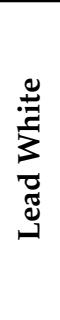 & $\begin{array}{l}\widetilde{Z} \\
\stackrel{\Xi}{J} \\
\widetilde{d} \\
\simeq\end{array}$ & : & 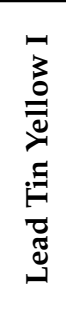 & 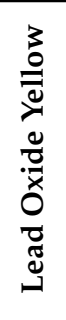 & 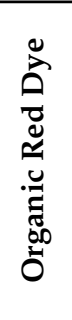 & 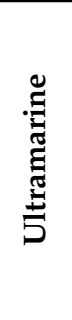 & 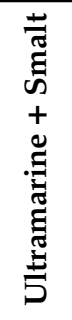 & 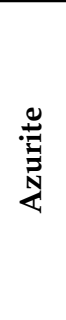 & & 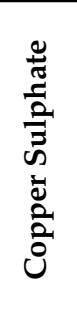 & 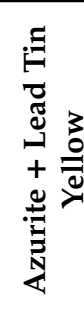 & 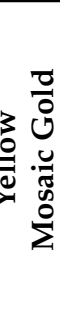 \\
\hline FM Marlay cutting It. 20 & $x$ & $x$ & (ink only) & $x$ & & $x$ & & & $x$ & & $x$ & & $x$ \\
\hline FM Marlay cutting It. 62 & $x$ & $x$ & $x$ & & & & $x$ & & & $x$ & & & $X$ \\
\hline FD 22171 & $x$ & $x$ & $x$ & & $x$ & $x$ & $x$ & & & * & * & & \\
\hline FM MS McClean 201.17 & $x$ & & $x$ & $x$ & & & $x$ & $x$ & $x$ & & & $x$ & $X$ \\
\hline
\end{tabular}

The most interesting comparisons that can be drawn amongst all of the works analysed, which are attributed to Cortese, regard the red/orange, blue and green pigments. Red lead and vermilion are both used by the artist, usually in separate areas of different colour. For example, in the simple composition depicted on FM Marlay cutting It. 62 [14] (p. 108), red lead is used for the orange initial, whereas vermilion is found in the red robes worn by some of the figures in the miniature itself. The same two pigments were however deployed by Cortese in a much more nuanced manner in FD 22171 [15] (pp. 373-375) and in two of the folios analysed in Psalter N (7v and 36r). In these images, red lead was used to provide light-coloured highlights over darker red areas painted with vermilion-be they decorative leaves in the initials and borders, or in the figures' robes (as can be seen in the Cini miniature). The varying use of these two materials across Psalter $\mathrm{N}$ is worthy of further investigation, vis-à-vis the ongoing cataloguing effort. The technical evidence might suggest the presence of up to two additional artists at work on this extensively illuminated volume, whose decorative scheme Cortese was most certainly supervising and contributing to directly.

Azurite is by far the most common blue pigment identified in the Cortese works analysed; it is used exclusively in the two San Giorgio volumes and in FM Marlay cutting It. 20 [14] (p. 109). Ultramarine, on the other hand, is the only blue pigment found in FM Marlay Cutting It 62 and in the Cini fragment. The fourth fragment (FM MS McClean 201.17 [14] (pp. 118-119)), also contains azurite, which is used for 'marginal' areas of the decoration. All of the blue draperies, windows and the background of the fragmentary text present to the right of the image, contain instead a mixture of ultramarine and smalt. 
No less than four different green pigments and mixtures were identified on the miniatures by Cortese included in this study, despite the relatively small number of images analysed. Together with the information obtained about red and blue pigments, this result highlights the extreme variability of this artist's palette. Further analyses of additional miniatures attributed to Cortese would be extremely interesting, in order to establish and understand his patterns of use, perhaps linked to the chronology of the works and relative availability of specific materials, perhaps to the optical effects intended.

\subsection{The Use of Smalt in 15th-Century Venetian Miniatures}

Smalt is a ground blue potash glass whose colour is due to the presence of small amounts of cobalt. It is infrequently found in Western European artworks before 1450; after this date, it appears to have gradually spread until the mid-16th century, when it starts to be commonly used by painters all over Europe $[17,18]$. While smalt has an attractive blue hue resembling that of ultramarine when well preserved, it is extremely unstable in an oil medium, its colour turning to a dull grey. However, smalt does not as easily lose its colour when bound in media different from oil, such as gum Arabic, which is perhaps why it was used by Venetian manuscript illuminators, seemingly a few decades before it was used by local easel painters. The use of this pigment might attest a relationship between glass-makers and illuminators; this is obviously of particular interest in the context of Venetian art. In addition to the manuscripts discussed here, a mixture of smalt and ultramarine has also been identified in a few other, slightly earlier, fragments, painted in Venice by the so-called Master of the Murano Gradual [10]. It is worth noting that no traces of bismuth were detected in the blue smalt pigment in any of the instances mentioned. This is consistent with the manuscripts dating to before 1520, when anecdotal and experimental evidence suggests a change in the technology for production of the raw materials used to make smalt $[17,19]$.

Considering the production context of all of these manuscripts, it is plausible that the illuminators may have 'extended' ultramarine with smalt, which would have been widely available in Venice in the 15th century. In a glass-production centre such as Venice, illuminators would reasonably have employed smalt similarly to how artists elsewhere would use azurite: to reduce the cost of materials by mixing it with the costly ultramarine, potentially in painted areas of 'lesser' importance, or simply to obtain different hues. Questions which deserves further investigation are whether such mixtures were available for artists to purchase ready-made, and if that is the case, whether they were aware of their mixed composition.

Additionally, with specific regard to the work of the Master of Antiphonary $Q$, the fact that smalt was only identified in some of the analysed images attributed to him deserves further attention. This result may provide clues useful to separate the work of two different artists, who have so far been conflated into one by manuscript scholars.

\subsection{The Use of Metallic Bismuth in Decorative Borders}

As far as it has been revealed by technical analyses so far, bismuth compounds were rarely used by artists. French illuminator Jean Bourdichon (c. 1457-1521) famously used metallic bismuth, deployed as a warm grey pigment, throughout his career [12,20]. The earliest use of bismuth securely identified in works of art dates to c. 1440, when it appears to have been used to imitate or substitute silver in a Czech manuscript [21]. Metallic bismuth, used as a black pigment, has also been found in the polychrome decoration of a late 15th century chapel in central Bohemia [22]; in late 15th- and 16th-century easel paintings by a number of Italian artists [23]; in 16th-century German and Swiss wooden objects (including items of furniture, boxes and cabinets) [24]; and in a mid-16th century German Bible, used in the metallic layers of its coloured etchings [20,24] (where the Bible is incorrectly identified as ' 15 th century', but a specific date of 1552 or 1557 is given in an endnote).

The mines at Schneeberg in Saxony are likely to have been the main source of bismuth in the 16th century. Mining of this metal began in Schneeberg around 1460, which has often been considered the earliest possible date for use of this material as a pigment [23]. However, the earliest recipe 
of the manufacture of 'silver ink' - which in fact contains bismuth, 'to write so that it looks like silver'-is found in a 1384 manuscript, currently in the library of the Germanisches Nationalmuseum in Nuremberg [24]. Other 14th and 15th century manuscripts include recipes for bismuth-based materials; most recipes state that they can be used 'as a good ink', whereas only a few discuss its use as a paint medium [24]. It is perhaps unsurprising, then, that the presence of bismuth in the San Giorgio manuscripts—one of its very earliest scientifically demonstrated uses as an artist's material—appears to exploit its ink-like qualities.

\section{Conclusions}

The non-invasive, multi-technique analysis of ten 15th century manuscripts belonging to the abbey of San Giorgio Maggiore in Venice produced a number of interesting results, summarised in this article. The identification of pigments and painting techniques was achieved by means of a multi-step analytical protocol including both imaging and spectroscopic methods, used in combination for a comprehensive characterisation of the materials. The study provided interesting information about the work of individual Venetian illuminators and about the possible methods of production of the specific manuscripts. These results are now being evaluated vis-à-vis ongoing art-historical research on the entire set of volumes.

Additionally, the identification of 'unusual' materials such as smalt and metallic bismuth highlights the research potential of taking a much closer look to the materials used by 15th-century Venetian artists. During the Middle Ages and the Renaissance, Venice was a thriving cultural and commercial hub, at the crossroad of trade routes going from East to West, and from North to South. The two main historic sources of cobalt-needed to produce smalt-are in Iran and Saxony. The first was most likely exploited by Armenian illuminators, who used smalt as early as the 13th century [25], the second certainly by 16th-century Flemish ones. Further, more specific analyses of Venetian manuscripts containing smalt, together with analyses of Iranian cobalt ores, may reveal the geographic origin of the cobalt, which made its way to Venice. A closer look at decorative borders in manuscripts produced both North and South of the Alps during the 15th century, at a time when print was just about to radically change book production, may reveal a more widespread use of bismuth inks than it has so far been possible to envisage. All together, these future research endeavours centred around the material world of 15th-century Venetian art may help shed further light on the commercial history of this well-connected city, and on the networks of artists who lived and worked there.

Supplementary Materials: The following are available online at http://www.mdpi.com/2571-9408/2/2/103/s1, Antiphonary M, folio 8v-elemental maps.

Author Contributions: Conceptualization and methodology, P.R.; analytical investigation and final draft editing, A.M., P.R., S.L., C.R., L.C.; writing—original draft preparation, A.M.; writing—review and editing, P.R.

Funding: Travel to San Giorgio Maggiore to undertake analyses was funded by the Abbey of San Giorgio Maggiore. A.M.'s research fellowship, during which this work was undertaken, was funded by the Zeno-Karl Schindler Foundation.

Acknowledgments: The authors wish to acknowledge Stella Panayotova (Fitzwilliam Museum) as well as Chiara Ponchia and Federica Toniolo (University of Padua) for fruitful discussions and for providing art-historical background on the manuscripts analysed. Thanks are also due to John Lancaster (Fitzwilliam Museum), who made the Perspex support used to set up the manuscripts during XRF scanning.

Conflicts of Interest: The authors declare no conflict of interest. The funders had no role in the design of the study; in the collection, analysis, or interpretation of data; in the writing of the manuscript, or in the decision to publish the results.

\section{References}

1. Ricciardi, P.; Schmidt Patterson, C. Science of the Book. In A Handbook of the Art and Science of Illuminated Manuscripts; Panayotova, S., Ed.; Harvey Miller/Brepols: London, UK; Turnhout, Belgium, forthcoming.

2. Pessanha, S.; Manso, M.; Carvalho, M.L. Application of spectroscopic techniques to the study of illuminated manuscripts: A survey. Spectrochim. Acta Part B 2012, 71-72, 54-61. [CrossRef] 
3. Aceto, M.; Agostino, A.; Fenoglio, G.; Idone, A.; Gulmini, M.; Picollo, M.; Ricciardi, P.; Delaney, J.K. Characterisation of colourants on illuminated manuscripts by portable fibre optic UV-visible-NIR reflectance spectrophotometry. Anal. Methods 2014, 6, 1488-1500. [CrossRef]

4. Taccetti, F.; Castelli, L.; Czelusniak, C.; Gelli, N.; Mazzinghi, A.; Palla, L.; Ruberto, C.; Censori, C.; Lo Giudice, A.; Re, A.; et al. A multipurpose X-ray fluorescence scanner developed for in situ analysis. Rend. Lincei Sci. Fis. Nat. 2019, 30, 307-322. [CrossRef]

5. Bell, I.M.; Clark, R.J.H.; Gibbs, P.J. Raman spectroscopic library of natural and synthetic pigments (pre1850 AD). Spectrochim. Acta Part A 1997, 53, 2159-2179. [CrossRef]

6. Burgio, L.; Clark, R.J.H. Library of FT-Raman spectra of pigments, minerals, pigment media and varnishes, and supplement to existing library of Raman spectra of pigments with visible excitation. Spectrochim. Acta Part A 2001, 57, 1491-1521. [CrossRef]

7. Toniolo, F.; Ponchia, C. L'InCanto Della Miniature. I Corali di San Giorgio Maggiore a Venezia, 2020; forthcoming.

8. Caggiani, M.C.; Cosentino, A.; Mangone, A. Pigments Checker version 3.0, a handy set for conservation scientists: A free online Raman spectra database. Microchem. J. 2016, 129, 123-132. [CrossRef]

9. García-Bucio, M.A.; Casanova-González, E.; Ruvalcaba-Sil, J.L.; Arroyo-Lemus, E.; Mitrani-Viggiano, A. Spectroscopic characterization of sixteenth century panel painting references using Raman, surface-enhanced Raman spectroscopy and helium-Raman system for in situ analysis of Ibero-American Colonial paintings. Philos. Trans. R. Soc. A 2016, 374, 20160051. [CrossRef] [PubMed]

10. Ricciardi, P.; MacLennan, D.; Bertolotti, G.; Bucklow, S.; Delaney, J.K.; Dooley, K.; Gabrieli, F.; Schmidt Patterson, C. A non-invasive multi-analytical study of the limits of detection of smalt in ultramarine mixtures. Herit. Sci.. manuscript in preparation.

11. Trentelman, K. A note on the characterization of bismuth black by Raman microspectroscopy. J. Raman Spectrosc. 2008, 40, 585-589. [CrossRef]

12. Burgio, L.; Clark, R.J.H.; Hark, R.R.; Rumsey, M.S.; Zannini, C. Spectroscopic Investigations of Bourdichon Miniatures: Masterpieces of Light and Color. Appl. Spectrosc. 2009, 63-66, 611-620. [CrossRef] [PubMed]

13. Panayotova, S. Cristoforo Cortese in Cambridge. In Miniatura. Lo Sguardo e la Parola: Studi in Onore di Giordana Mariani Canova; Toniolo, F., Toscano, G., Eds.; Silvana Editoriale: Cinisello Balsamo, Italy, 2012; pp. 189-190.

14. Morgan, N.; Panayotova, S.; Reynolds, S. (Eds.) A Catalogue of Western Book Illumination in the Fitzwilliam Museum and the Cambridge Colleges. Part Two: Italy and the Iberian Peninsula; Harvey Miller/Brepols: London, UK; Turnhout, Belgium, 2011.

15. Medica, M.; Toniolo, F. (Eds.) Le Miniature della Fondazione Giorgio Cini; Silvana Editoriale: Cinisello Balsamo, Italy, 2016.

16. Panayotova, S. (Ed.) COLOUR. The Art and Science of Illuminated Manuscripts; Harvey Miller/Brepols: London, UK; Turnhout, Belgium, 2016.

17. Berrie, B.H. Mining for Color: New Blues, Yellows, and Translucent Paint. Early Sci. Med. 2015, 20, 308-334. [CrossRef]

18. Mühlethaler, B.; Thissen, J. Smalt. In Artists' Pigments. A Handbook of Their History and Characteristics; Roy, A., Ed.; National Gallery of Art: Washington, DC, USA, 1993; Volume 2, pp. 113-130.

19. Seccaroni, C.; Haldi, J.-P. Cobalto, Zaffera, Smalto Dall'antichità al XVIII Secolo; Laboratorio Tecnografico ENEA: Frascati, Italy, 2016; pp. 11-32, 45-64.

20. Trentelman, K.; Turner, N. Investigation of the painting materials and techniques of the late-15th century manuscript illuminator Jean Bourdichon. J. Raman Spectrosc. 2009, 40, 577-584. [CrossRef]

21. Dřevíkovská, J.; Ohlídalová, M.; Boldan, K. Srovnání Vzácných Iluminovaných Rukopisů Připisovaných Mistru Šelmberské Bible (Comparison of Precious Illuminated Manuscripts Attributed to 'Master of Šelmberk Bible'); Sborník z Konference Konzervátorů a Restaurátorů; Technické museum v Brnĕ: Brno, Czech Republic, 2008; pp. 61-67.

22. Čechák, T.; Trojek, T.; Šefců, R.; Chlumská, Š.; Třeštíková, A.; Kotrlý, M.; Turková, I. The use of powdered bismuth in Late Gothic painting and sculpture polychromy. J. Cult. Herit. 2015, 16, 747-752. [CrossRef]

23. Spring, M.; Grout, R.; White, R. 'Black Earths': A Study of Unusual Black and Dark Grey Pigments used by Artists in the Sixteenth Century. Natl. Gallery Tech. Bull. 2003, 24, 96-114. 
24. Gold, R. Reconstruction and Analysis of Bismuth Painting. In Painted Wood: History and Conservation, Proceedings of a Symposium Organized by the Wooden Artifacts Group of the American Institute for Conservation of Historic and Artistic Works; Dorge, V., Howlett, F.C., Eds.; Getty Conservation Institute: Los Angeles, CA, USA, 1998; pp. 166-178.

25. Turner, N.K.; Schmidt Patterson, C. New Discoveries in the Painting Materials in the Medieval Mediterranean: Connections between Manuscript Illumination and Glass Technology during the Byzantine Era, c.1100-1300. In Manuscripts in the Making Art and Science; Panayotova, S., Ricciardi, P., Eds.; Harvey Miller/Brepols: London, UK; Turnhout, Belgium, 2017; Volume 1, pp. 187-199.

(C) 2019 by the authors. Licensee MDPI, Basel, Switzerland. This article is an open access article distributed under the terms and conditions of the Creative Commons Attribution (CC BY) license (http://creativecommons.org/licenses/by/4.0/). 